\title{
Simultaneous bilateral posterior fracture dislocation of the shoulders in a young man with unexpected severe vitamin $\mathrm{D}$ deficiency
}

This article was published in the following Dove Press journal:

International Journal of General Medicine

3 May 2012

Number of times this article has been viewed

\author{
Deborah O'Neill' \\ Jagdish R Nair' \\ Khalid A Binymin ${ }^{1,2}$ \\ 'Rheumatology Unit, Southport \\ General Hospital, Southport, \\ ${ }^{2}$ Rheumatology Department, Liverpool \\ University, Liverpool, Merseyside, UK
}

\begin{abstract}
Simultaneous bilateral posterior fracture dislocation of the shoulders is a rare clinical presentation. There are three main etiologies described in the literature. Given that it presents with relatively uncharacteristic symptoms, in many cases it is diagnosed late. We present the case of a man who was admitted with bilateral posterior fracture dislocation of the shoulders following a seizure. Investigations revealed severe vitamin D deficiency as the principal contributory factor to his injury. This is an important association because failure to recognize and treat this can result in significant morbidity in susceptible groups.
\end{abstract}

Keywords: bilateral fracture, dislocation, shoulder, vitamin D deficiency

\section{Background}

Bilateral posterior fracture dislocation of the shoulders is a rare clinical presentation. It was first described by Mynter $^{1}$ in 1902. Posterior dislocation of the shoulder accounts for $1 \%-4 \%$ of all dislocations, while posterior fracture dislocations contributed to $0.9 \%$ of the 1500 dislocations observed by Neer. ${ }^{2,3}$

The three main etiologies described in the literature are termed the "triple $\mathrm{E}$ syndrome", which comprises epilepsy or any convulsive seizure, extreme trauma, and electric shock. Seizures account for approximately $50 \%$ of all cases, trauma $45 \%$, and electrocution less than $5 \%{ }^{4}$

Posterior fracture dislocation of the shoulder itself presents with relatively uncharacteristic symptoms; therefore, it is unsurprising that a precise initial diagnosis is usually missed. The main symptom observed is a reduction in movement of the affected shoulder, particularly loss of external rotation. The above injury can occur in patients with violent muscle contractions as in an epileptic fit when the bone architecture is affected by conditions like osteomalacia and osteoporosis. Our case is illustrative of this pathogenetic role.

\section{Case report}

A 45-year-old Caucasian male presented to the accident and emergency department with the chief complaint of bilateral shoulder pain, generalized aches, fatigue, and morning stiffness of 24 hours' duration. He thought his pain was related to a series of low-intensity shoulder exercises including modern Tai-chi, a traditional Chinese exercise that he had performed the previous day. On the morning of admission, his family reported him to be vague, off-color, and similar to his appearance when he had a single witnessed seizure several years earlier. His past medical history included
Correspondence: Khalid A Binymin Southport and Ormskirk NHS TRUST, Kew, Southport, England, UK, PR8 6PN

$\mathrm{Tel}+44$ I704 54747I

Fax +44I 704704479

Email kbinymin@nhs.net 
obesity and ischemic cardiomyopathy, for which he had had an automatic implantable cardioverter defibrillator inserted some years earlier. He did not have any previous history of myalgia or arthralgia. He was taking beta blockers and angiotensin-converting enzyme inhibitors, and denied alcohol and illicit drug use. He had never received treatment for epilepsy. There was no family or personal history of osteomalacia, osteoporosis, or fractures.

His body mass index was 38.2. Musculoskeletal examination of the shoulders showed grade 3 tenderness and reduced movements in all planes. There was no other bony tenderness elsewhere. Tongue biting was not noted. Initial routine blood analysis was normal and electrocardiography did not reveal any arrhythmia. Chest x-ray showed cardiomegaly with an automatic implantable cardioverter defibrillator in situ. Shoulder x-rays performed in view of his symptoms showed bilateral proximal humeral fractures (Figures 1 and 2).

A computed tomography scan of the shoulders confirmed a large impacted fracture of the left humeral head which was displaced posteriorly and a fracture of the anatomical neck of the right humerus with posterior dislocation (Figure 3).

A dual-emission x-ray absorptiometry (DEXA) scan showed a $t$ score of -2.6 at the lumbar spine and a $t$ score of -1.2 at the hip. Biochemical tests revealed normal calcium and phosphate levels, alkaline phosphatase raised at $264 \mathrm{IU} / \mathrm{L}$ (normal 40-140 IU/L), parathyroid hormone elevated at $9.1 \mathrm{pmol} / \mathrm{L}$ (normal $0.4-5.5 \mathrm{pmol} / \mathrm{L}$ ) and 25-hydroxyvitamin $\mathrm{D}_{2}<5 \mathrm{ng} / \mathrm{mL}$ (low) with 25 -hydroxyvitamin $\mathrm{D}_{3}$ of $6.4 \mathrm{ng} / \mathrm{mL}$ $(<10 \mathrm{ng} / \mathrm{mL}$ indicates severe deficiency and $10-20 \mathrm{ng} / \mathrm{mL}$ indicates insufficiency). Serum collagen type 1 cross-linked C-telopeptide was elevated above the normal range at $8 \mu \mathrm{g} / \mathrm{L}$ $(1.72 \pm 0.93 \mu \mathrm{g} / \mathrm{L})$ serving as a marker of bone resorption. Urinary calcium excretion was normal. Nutritional assessment of his eating habits revealed no specific dietary restrictions.

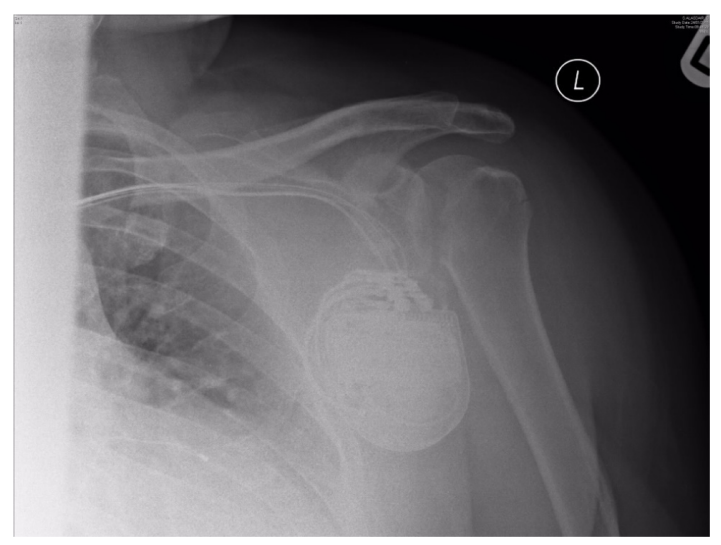

Figure I Anteroposterior film of left shoulder.

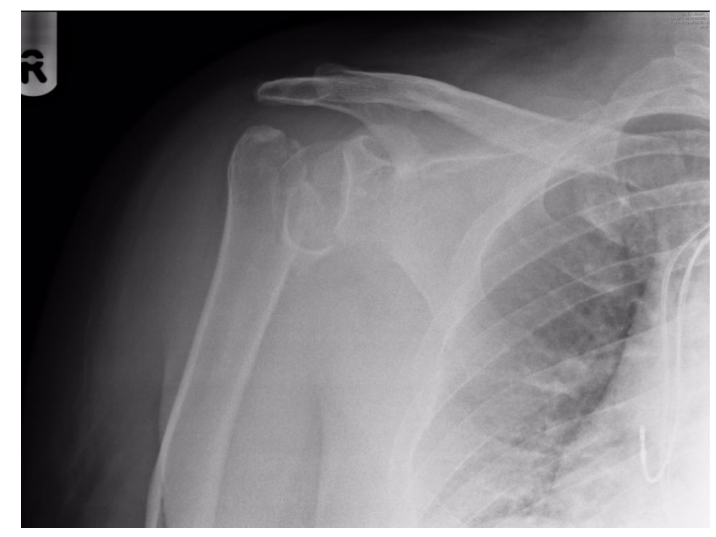

Figure 2 Anteroposterior film of right shoulder.

The full clinical picture was consistent with severe vitamin D deficiency and osteomalacia. A malabsorption screen, including a celiac screen, was negative. The patient was commenced on vitamin D replacement therapy. Further investigations were initiated to confirm idiopathic epilepsy and neurology advice was sought, given that this was the second seizure. The automatic implantable cardioverter defibrillator was interrogated, which excluded ventricular tachyarrhythmia and malfunctioning of the device as a cause of his seizures. He subsequently underwent a right shoulder hemiarthroplasty and left humeral internal fixation.

\section{Discussion}

Bilateral posterior fracture-dislocation is an uncommon orthopedic injury, with a peak incidence in middle-aged men. ${ }^{3}$ Because the clinical manifestation varies greatly, it is often difficult to diagnose early.

Seizures are a well recognized cause of bilateral posterior fracture-dislocation of the shoulders. The mechanism of injury was reported by Shaw in $1971 .{ }^{5}$ It is thought that during the convulsive episode, the shoulder is held in adduction, flexion, and internal rotation, and it is the contraction of the shoulder girdle muscles which force the humeral head superiorly and posteriorly. The final step in the process is due to infraspinatus, teres minor, deltoid, latissimus dorsi, and teres major, which provide the force necessary to produce dislocation. Similarly, bilateral hip fracture can occur as a rare complication of seizures. ${ }^{6,7}$

Vitamin D insufficiency is common in Europe and Asia. In 2010, Pearce and Cheetam ${ }^{8}$ carried out a survey across the UK which demonstrated that more than $50 \%$ of the adult population have insufficient levels of vitamin $\mathrm{D}$ and that $16 \%$ have severe deficiency during winter and spring. 


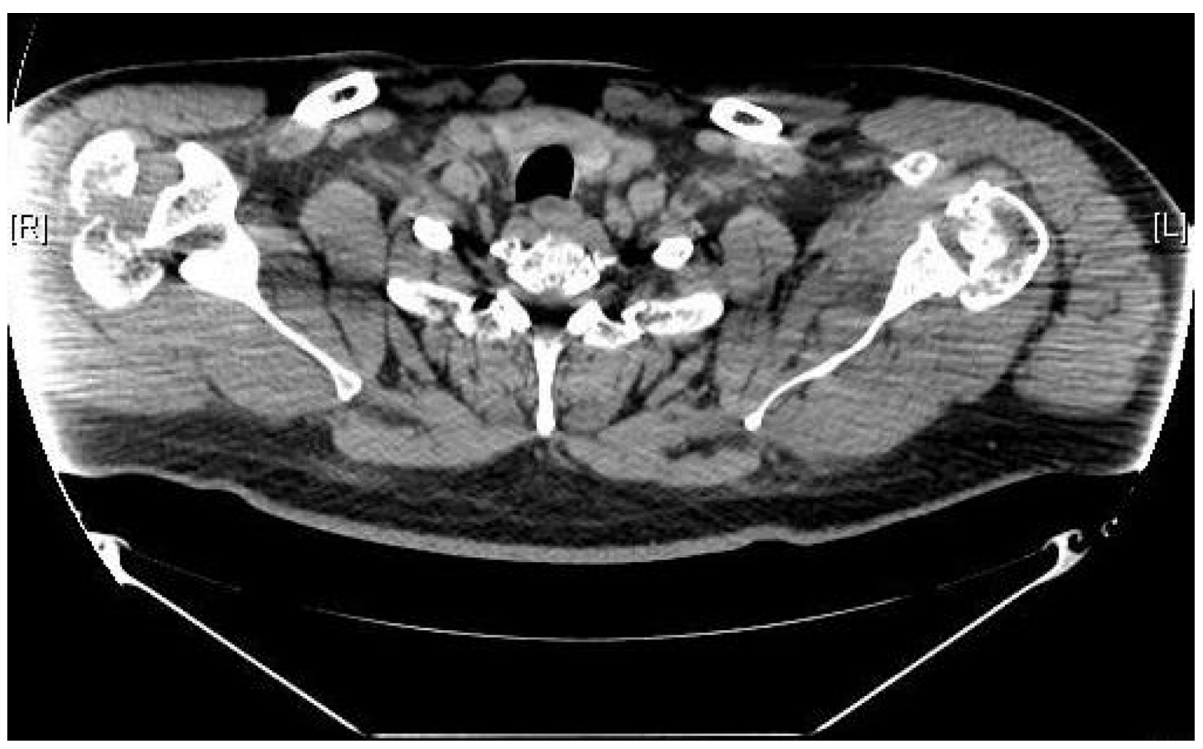

Figure 3 Computed tomography of right and left shoulder.

The most at-risk groups include people with pigmented skin, the elderly, obese individuals, those with malabsorption, short bowel, or renal or liver disease, and individuals taking anticonvulsants or highly active antiretroviral drugs. ${ }^{9}$

In adults, vitamin D deficiency may present with musculoskeletal pain and weakness. ${ }^{9}$ Low bone density on DEXA scanning, or osteopenia on plain radiography, may also reflect osteomalacia, and these findings warrant assessment of vitamin D status, ${ }^{10}$ as demonstrated in our case.

In our patient, the clinical findings coupled with the radiologic investigations confirmed the diagnosis of bilateral posterior fracture dislocation of the shoulders, which led us to identify a history of epileptic seizure and severe vitamin D deficiency. We believe that lack of sun exposure secondary to poor exercise tolerance as a result of morbid obesity and heart failure was the prime factor responsible for the vitamin $\mathrm{D}$ deficiency in our patient. The calcium levels were within normal limits, but the degree of vitamin D deficiency in this case was severe enough to cause low bone density and eventually increased bone fragility. Normal calcium levels despite clear biochemical and radiologic evidence of established osteomalacia is often encountered as a physiologic consequence of secondary hyperparathyroidism, resulting in high parathyroid hormone levels and subsequent normalization of calcium levels in the blood. The combination of violent muscle contractions and low bone density were responsible for the simultaneous fracture of both humerus bones.

Despite uncharacteristic symptoms of fractures, prompt recognition and a focused investigation of the area concerned is important in order to minimize the risk of complications, which include nerve and vascular compromise. Comorbid conditions should be examined closely because they may influence the patient's recovery.

Our patient made a satisfactory postoperative recovery and has been commenced on vitamin D supplementation. It is of the utmost importance to identify the cause of seizures, whether metabolic, cardiac, or cerebral. Seizure management is necessary to prevent recurrence of the injury and further harm to the patient. It is also necessary to recognize that antiepileptic drugs can cause osteomalacia.

\section{Conclusion}

Few cases of bilateral posterior fracture dislocation of the shoulder have been reported. Seizures are the most common identifiable cause. Though we recognize convulsive episodes as being the prime factor responsible for the mechanism of simultaneous bilateral fractures, bone fragility as a result of concomitant metabolic bone disorder should be studied actively in this type of presentation. Screening for bone health, osteomalacia, and osteoporosis should be performed in all susceptible groups. Prompt investigation and treatment of the underlying cause is necessary to prevent further fractures and long-term joint damage.

\section{Disclosure}

The authors declare they have no competing interests in this work.

\section{References}

1. Mynter H. Subacromial dislocation from the muscular spasm. Ann Surg. 1902;36:117. 
2. Neer CS 2nd. Displaced proximal humeral fractures. Part I: Classification and evaluation. J Bone Joint Surg Am. 1970;52:1077-1089.

3. Neer CS 2nd. Displaced proximal humeral fractures. Part II: Treatment. J Bone Joint Surg Am. 1970;52:1090-1103.

4. Brackstone M, Patterson SD, Kertesz A. Triple "E" syndrome: Bilateral locked posterior fracture dislocation of the shoulders. Neurology. 2001;56:1403-1404.

5. Shaw JL. Bilateral posterior fracture-dislocation of the shoulder and other trauma caused by convulsive seizures. J Bone Joint Surg. 1971;53A:1437-1440.

6. Blanco JS, Dahir G, McCrystal K. Bilateral femoral neck fracture secondary to hypocalcemic seizure in skeletally immature patient. $\mathrm{Am}$ J Orthop. 1999;3:187-188.
7. Faraj AA. Bilateral simultaneous intra and extra capsular femoral neck fracture secondary to nutritional osteomalacia. Acta Orthop Belg. 2003;2:201-203.

8. Pearce S, Cheetam T. Diagnosis and management of vitamin D deficiency. Br Med J. 2010;340:b5664.

9. Hyppönen E, Power C. Hypovitaminosis D in British adults at age $45 \mathrm{y}$ : nationwide cohort study of dietary and lifestyle predictors. Am J Clin Nutr. 2007;85:860-868

10. Reginato AJ, Falasca GE, Pappu R, McKnight B, Agha A. Musculoskeletal manifestations of osteomalacia: report of 26 cases and literature review. Semin Arthritis Rheum. 1999;28:287-304.

\section{Publish your work in this journal}

The International Journal of General Medicine is an international, peer-reviewed open-access journal that focuses on general and internal medicine, pathogenesis, epidemiology, diagnosis, monitoring and treatment protocols. The journal is characterized by the rapid reporting of reviews, original research and clinical studies across all disease areas.
A key focus is the elucidation of disease processes and management protocols resulting in improved outcomes for the patient. The manuscript management system is completely online and includes a very quick and fair peer-review system. Visit http://www.dovepress.com/ testimonials.php to read real quotes from published authors.

Submit your manuscript here: http://www.dovepress.com/international-journal-of-general-medicine-journal 